ISSN 0258-7122

Bangladesh J. Agril. Res. 40(3): 399-407, September 2015

\title{
BRINJAL SHOOT AND FRUIT BORER INFESTATION IN RELATION TO PLANT AGE AND SEASON
}

\author{
M. A. MANNAN ${ }^{1}$, K. S. ISLAM ${ }^{2}$ AND M. JAHAN ${ }^{2}$
}

\begin{abstract}
Brinjal shoot and fruit borer infestation varied significantly in relation to plant age and season. The peak shoot infestation was $8.56 \%$ in the $10^{\text {th }}$ week of transplanting. No infestation of BSFB was found up to 5 weeks of transplanting. The shoot infestation was initiated in the $6^{\text {th }}$ week of transplanting which increased to a little higher level in the next week. Then it showed an exponential increase of shoot infestation up to $10^{\text {th }}$ week after which it declined steadily. Flowering and fruit setting started in the $9^{\text {th }}$ week of transplanting. Infestation of brinjal shoot and fruit borer (BSFB) shifted to fruits from shoots causing a steady declined in the trend of shoot infestation. Plant age had significant effect $\left(\mathrm{r}^{2}=0.87\right)$ on fruit infestation. The fruit infestation reached the highest level $(38.56 \%)$ in $14^{\text {th }}$ week of transplanting. However, the level of infestation at different ages of the plant may vary depending on the location, temperature, variety etc. The shoots and fruits of brinjal plant were found to be infested by BSFB throughout the year, although the level of infestation varied. Maximum shoot and fruit infestation was found in the month of September.
\end{abstract}

Keywords: Brinjal shoot and fruit borer, Leucinodes orbonalis, infestation, plant age, seasonal fluctuation.

\section{Introduction}

Brinjal is a versatile and economically important vegetable among small-scale farmers and low income consumers of the entire universe (FAO, 2000). It is the leading vegetable in the country and ranks first among summer and winter vegetables in terms of total acreage. Asia has the largest brinjal production which comprises about $90 \%$ of the total production area and $87 \%$ of the world production (FAO, 2000). Brinjal, an economically important commercial crop, is reported variedly to be infested by more than 36 pests (Regupathy et al., 1997) from the time of its planting to harvest. Among them, brinjal shoot and fruit borer (BSFB), Leucinodes orbonalis Guenee is considered to be the most serious pest of brinjal and it has become a very serious production constraint in all brinjal growing countries (Alam et al., 2003). The brinjal shoot and fruit borer is the key insect pest of brinjal in Bangladesh (Alam and Sana, 1964), India (Tewari and Sardana, 1990) and other countries of the world (Dhankar, 1988). The fruit infestation by this pest may be as high as 67\% (BARI 1991). It is very difficult to control since it feeds inside the shoots and fruits (Ghosh and Senapati, 2009).

${ }^{1}$ Regional Agricultural Research Station, Jamalpur. ${ }^{2}$ Department of Entomology, Bangladesh Agricultural University, Mymensingh, Bangladesh. 
Over $95 \%$ farmers recognized BSFB as the most serious pest and nearly all of them used only chemical insecticides to combat (Alam et al., 2003). Sometimes, the yield loss caused by this pest has been estimated more than $85 \%$ (Rashid et al., 2003) and 86\% (Ali et al., 1996) in Bangladesh, 85.8\% (Patnaik, 2000), 75\% (Singh et al., 2005) and 95\% (Naresh et al., 1986) in India. Brinjal production is seriously affected by damage caused by brinjal shoot and fruit borer (AVRDC, 2001). The management practices mainly include spraying different insecticides which cause several pesticide related complications and leave toxic residues in the fruits, reduce the beneficial arthropods and create pollution of the environment. The vegetable growers of Jessore region spray insecticide almost every day or every alternate day in the brinjal field with as many as 84 times in a season (BARI, 1994). It is now urgently required to find out an alternative and non-insecticidal method for controlling this pest. Frequent use of systemic insecticides makes the vegetables poisonous, ecologically unsafe and economically unviable. It is easy to replace the poisonous chemicals with knowledge through transplanting the seedlings at appropriate time and understanding the knowledge of seasonal fluctuation of temperature and other abiotic factors. Very few farmers had knowledge on the infestation status of BSFB in relation to plant age and seasonal fluctuation of temperature. Therefore, the present study was undertaken to know the effects of plant age of brinjal and seasonal variation on the infestation of BSFB.

\section{Materials and method}

An experiment was conducted in the field of Entomology Division, Bangladesh Agricultural University, Mymensingh during September 2008 to October 2009 on the incidence of BSFB in relation to plant age and season. The seedlings were raised in a seed bed. Variety was BARI Begoon 8 . The land was prepared by ploughing and laddering and fertilized with organic manure such as cow dung @ $10 \mathrm{~m}$ ton/ha, 7 days before final land preparation and chemical fertilizer Urea @ $150 \mathrm{~kg} / \mathrm{ha}$, TSP @ $100 \mathrm{~kg} / \mathrm{ha}$ and MP @ $150 \mathrm{~kg} / \mathrm{h}$. The whole TSP and MP and $1 / 3$ of Urea were applied during the final land preparation. Rest of the Urea was applied in two splits- one 30 days and other 50 days after planting. The individual plot size was $4.5 \mathrm{~m} \times 4.2 \mathrm{~m}$. The seedlings were planted in September 2008 and March 2009 with spacing $75 \mathrm{~cm}$ in between lines and $60 \mathrm{~cm}$ in between plants. Irrigation and other cultural operations were done as and when necessary. Ten plots were made for recording data and each plot was treated as one replication. No control measure was taken except the removal of shoots and fruits at the time of data collection. Infestation of BSFB to the shoots and fruits was monitored weekly after establishment of the plant in the field and continued to the last harvest of the brinjal fruits. Shoot damage was recorded by counting the infested shoots from 10 randomly selected plants. Percentage of shoot damage was calculated from damaged and healthy shoots. The number of infested and 
healthy brinjal fruits per plot were recorded at each harvest. The percentage of infestation by number was calculated using the number of infested and total brinjal fruits. At each count the affected shoots and fruits were removed and harvested. Incidence of BSFB in different months was calculated from the pooled weekly data. The correlations between seasonal incidence and environmental factors such as temperature, humidity and rainfall were determined.

\section{Results and Discussion}

Infestation level of BSFB with plant age: After transplanting the brinjal seedlings, it was monitored weekly for BSFB infestation. Infestation by BSFB was different in plant of different ages (Figure 1). The peak shoot infestation was $8.56 \%$ in the $10^{\text {th }}$ week of transplanting. No infestation of BSFB was found up to 5 weeks of transplanting. The shoot infestation was initiated in the $6^{\text {th }}$ week of transplanting which increased to a little higher level in the next week. Then it showed an exponential increase of shoot infestation up to the $10^{\text {th }}$ week after which it declined steadily. Flowering and fruit setting started in the $9^{\text {th }}$ week. Infestation of BSFB shifted to fruits from shoots causing a steady decline in the trend of shoot infestation. There was no significant correlation $\left(r^{2}=0.17\right)$ between plant age and shoot infestation.

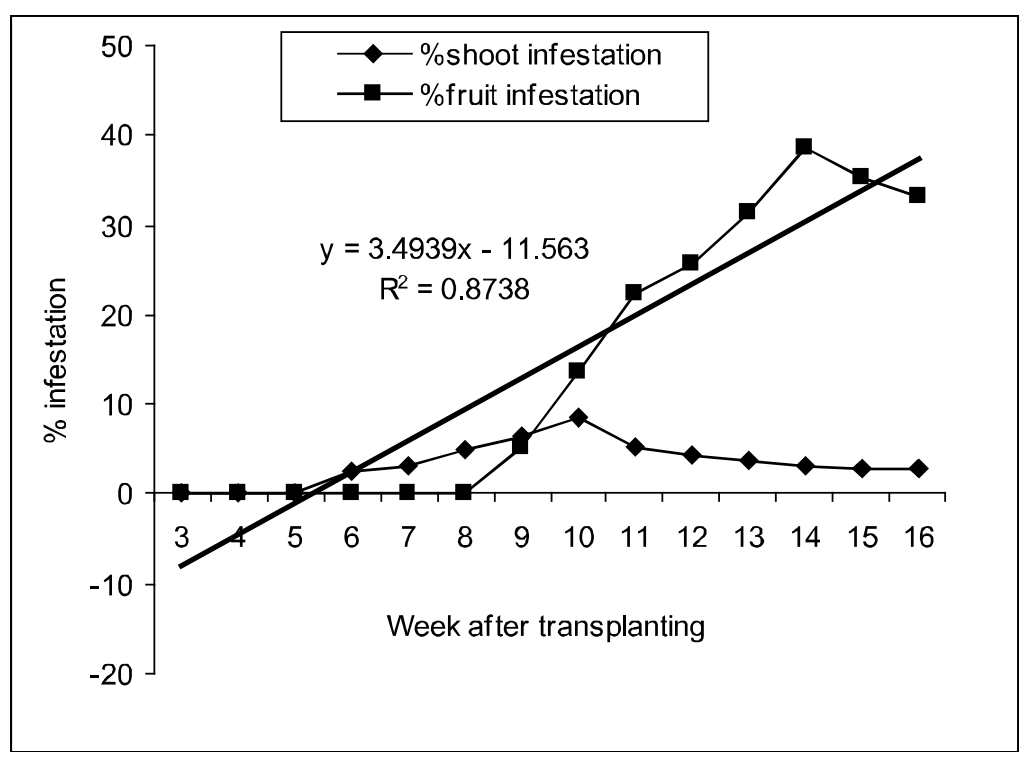

Figure 1. Effect of plant age on the infestation of $\boldsymbol{L}$. orbonalis

On the other hand, plant age had significant effect $\left(r^{2}=0.87\right)$ on fruit infestation which started in $9^{\text {th }}$ week of transplanting and showed $5.13 \%$ infestation. Then the fruit infestation increased rapidly showing a distinct increasing trend. The fruit infestation reached to its highest level $(38.56 \%)$ in $14^{\text {th }}$ week of 
transplanting. Thereafter, a little decline of fruit infestation was observed. It is evident that older plants suffered far more from the attack of BSFB and caused higher damage to the brinjal plants especially to the fruits. However, the level of infestation at different ages of the plant may vary depending on the location, temperature, variety etc. Therefore, in the early stage of the plant growth the pest BSFB is not a serious problem to brinjal cultivation. The management option should be selected depending on the level of BSFB infestation. In general, the brinjal growers may not need to adopt any chemical control measures until the plant reaches its maximum vegetative stage or pre-flowering stage as the commencement of infestation is noticed during that stage.

Several authors reported that the infestation of BSFB depends on plant age. Hossain et al., (2002) reported that plant age had significant effect on the incidence of brinjal shoot and fruit borer. They showed the highest infestation (32.80\%) of BSFB at 70 days after transplanting which was statistically different from the infestation $(5.18 \%)$ at 40 days after transplanting. They also reported that the rate of infestation gradually increased with the increase of plant age and then decreased in 100 days $(31.70 \%)$ after transplanting. Naik et al., (2008) showed the initial infestation of BSFB at 51 days after transplanting and thereafter the infestation gradually increased from 10.2 to $82.4 \%$ of shoot damage. It required 74 days after transplanting to reach a peak incidence of BSFB. Thereafter declined gradually with rise in temperature. In the present study the maximum shoot damage was found as $8.56 \%$ while Sharma and Chhibber (1999) reported that shoot damage was $15.89 \%$ at 29 days after transplanting of brinjal. The present finding on BSFB shoot infestation is different from the reports of Sharma and Chhibber (1999). It is noted that BSFB needs good vegetative growth of the plants for its infestation.

The level of BSFB infestation reported by Hossain et al., (2002) was $31.70 \%$ at 100 days after transplanting which is similar to the results of present study as it was recorded $31.25 \%$ fruit infestation at 91 days (13 weeks) after transplanting. The initial infestation of BSFB reported by Naik et al., (2008) was 51 days after transplanting which was near to 42 days (6 weeks) in the present study. The maximum shoot infestation was observed at 70 days (10 weeks) after transplanting in the present study which was also supported by Naik et al., (2008) although the level of infestation was different.

The results of the present study and the findings of above authors clearly indicate that the infestation of BSFB has relationship with the plant age showing higher pest incidence with the progress of plant growth. In other words, it can be said that infestation level is higher with sufficient vegetative growth of the plant and the presence of fruiting bodies. 


\section{Seasonal incidence of $L$. orbonalis}

The seasonal incidence of BSFB throughout the year in terms of shoot and fruit infestation is shown in Figure 2. Observation on the seasonal incidence of BSFB started in the month of September 2008 and continued up to October 2009. It was found that the level of fruit infestation was always higher than that of shoot infestation. The shoots and fruits of brinjal plant were found to be infested by BSFB throughout the year although the level of infestation varied. The shoot infestation was only $1.33 \%$ in January which was very similar in February. Then it started to increase steadily up to the month of September when maximum shoot infestation was observed. Then a marked decline was observed in October which showed a further slow decline thereafter up to the month of December.



Figure 2. Seasonal incidence of $L$. orbonalis in unsprayed brinjal field

The incidence of BSFB in fruits was calculated on the basis of the infestation of marketable size of the fruits. The fruit infestation was found $5.26 \%$ in the month of January which was minimum. Then a slight increase was found in the month of February which followed a sharp increase in March reaching 31.27\%. Thereafter the infestation of fruit was found to show a more or less steady increase up to the month of September when it reached its peak (56.38\%). Then a certain drop of infestation level occurred in the next month and reached to a significantly lower level as the winter progressed. In the month of December the level of infestation was found $12.25 \%$.

In addition, it was observed that a large number of flowers, flower buds and very young fruits were infested and damaged totally which were not included in the data. If they were included the level of fruit infestation would be much higher as it is evident in the Figure 3. The variation of BSFB infestation in shoots and fruits might be due to several abiotic and biotic factors. The temperature and 
rainfall had significant effect on the infestation level of brinjal shoot and fruits (Figure 4 and 5), although relative humidity had no significant effect.

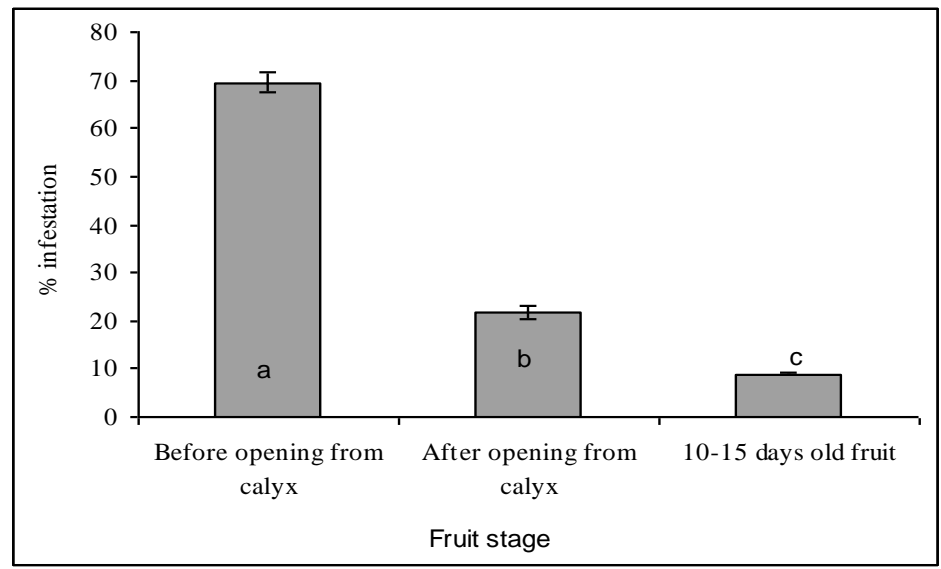

Figure 3. Percentage of BSFB infestation at different fruiting stages. Vertical bars represent \pm SE. Different letter(s) in different bars represent the significant difference $(p \geq 0.01)$



Figure 4. Relationship between temperature and the level of infestation of brijal shoots and fruits.

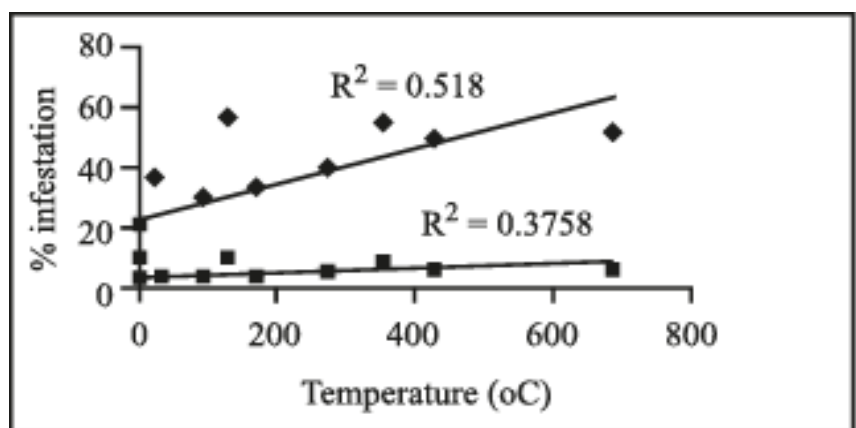

Figure 5. Relationship between rainfall $(\mathrm{mm})$ and the level of infestation of brinjal shoots and fruits. 
Naik et al., (2008) reported that incidence of L. orbonalis in terms of shoot infestation starts in February and there was no significant relationship of BSFB infestation with the temperature, RH and rainfall. Singh et al., (2000) reported that BSFB infestation was more serious on shoots during September to October ranging $73.33 \%$ to $86.66 \%$ with an intensity of 2.09 borers/plant when it reached the peak. They demonstrated a continuous decline of shoot infestation even to zero level in the month of October. This decline was related to the initiation of flowering and at this critical stage the borer infestation shifted from $33.33 \%$ to $66.66 \%$ in flowers and shoots which subsequently showed a greater decrease with the advent of winter season. Mahesh and Men (2007) reported that the infestation commenced from August with 21.2\% infestation and reached its peak during mid-October with $35.3 \%$ infestation at temperatures ranging between 21.4 and $33.0^{\circ} \mathrm{C}$, relative humidity of $45-86 \%$ with $2.7 \mathrm{~mm}$ rain and hot sunshine.

Although it was revealed that BSFB was prevailing in the brinjal field throughout the year, the level of infestation varied with the months and seasons of the year. The borer infestation was found to be very low during the winter months (December-February) which increased markedly in the summer months which was supported by Alam et al., (2006). They reported that summer brinjal crops suffered much greater pest damage than winter crops. Rashid et al., (2003) reported that $L$. orbonalis is difficult to control in the open field during summer time. The maximum level of borer infestation was found from June to September ranging from 51.35 to $56.38 \%$ when the average temperature, $\mathrm{RH}$ and rainfall were $28.74^{\circ} \mathrm{C}, 87.77 \%$ and $400.28 \mathrm{~mm}$, respectively.

The trend of BSFB infestation found in present investigation has similarity with the findings of Singh et al., (2000) and Mahesh and Men (2007) although the level of infestation was different. The seasonal variation of the pest level is common in many insects mostly for their poikelothermic developmental nature i.e., the development is directly proportional to the environmental temperatures. The variation of level of pest incidence in summer and winter may have the relationship with the biotic factors especially some parasitoids of BSFB. Although no attempt was made to investigate the synchronization between the pest and parasitoids in different environmental conditions, it was assumed that the tiny parasitoids were not able to withstand in the environmental condition when the rainfall was high during the month of June to September.

\section{References}

Alam, S.N., M.A. Rashid, F.M.A. Rouf, R.C. Jhala, J.R. Patel, S. Satpathy, T.M. Shivalingaswamy, S. Rai, I. Wahundeniya, A. Cork, C. Ammaranan and N.S. Talekar. 2003. Development of an integrated pest management strategy for eggplant fruit and shoot borer in South Asia. Technical Bulletin No. 28. AVRDC Publication Number 03-548. AVRDC-The World Vegetable Centre, Shanhua, Taiwan. 56p. 
Alam, S.N., M.I. Hossain, F.M.A. Rouf, R.C. Jhala, M.G. Patel, L.K. Rath, A. Sengupta, K. Baral, A.N. Shylesha, S. Satpathy, T.M. Shivalingaswamy, A. Cork and N.S. Talekar. 2006. Implemntation and promotion of an IPM strategy for control of eggplant fruit and shoot borer in South Asia. Technical Bulletin No. 36. AVRDC Publication Number 06-672. AVRDC-The World Vegetable Centre, Shanhua, Taiwan. 74p.

Alam, M.Z. and D.L. Sana. 1964. Biology of Leucinodes orbonalis Guenee in East Pakistan. pp. 192-200. In: M.Z. Alam, A. Ahmed, S. Alam, M.A. Islam (eds). A Review of Research, Division of Entomology (1947-1964). Agric. Inform. Serv. Dhaka.

Ali, M.I., A.K.M. Khorsheduzzaman, M.A. Karim and A. Ahmed. 1996. Effect of intercropping onion, garlic and coriander with brinjal on the infestation of brinal shoot and fruit borer. Bangladesh J. Agril. Res. 21(1): 58-63.

AVRDC. 2001. Eggplant insect pests: eggplant fruit and shoot borer. Shanhua, Taiwan. $74 \mathrm{p}$.

BARI. 1991. Management of the brinjal shoot and fruit borer, Leucinodes orbonalis Guen. pp.44-46. In: Annual Research Report. 1990-91. BARI, Gazipur, Bangladesh.

BARI. 1994. Integrated management for the brinjal shoot and fruit borer, Leucinodes orbonalis Guen. pp.94-96. In: Annual Research Report. 1993-94. BARI, Gazipur, Bangladesh.

Dhankar, B.S. 1988. Progress in resistance studies in eggplant (Solanum melongena L.) against shoot and fruit borer (Leucinodes orbonalis) infestation. Trop. Pest Manage. 34:343-345.

FAO. 2000. Area and production of aubergines. Year book. 48: 136.

Ghosh, S.K. and S.K. Senapati. 2009. Seasonal fluctuation in the population of Leucinodes orbonalis Guenee in the sub-himalayan region of West Bengal, India and its control on eggplant (Solanum melongena). Prec. Agril. 10(5): 443-449.

Hossain, M.M., M. Shajahan, and M.A. Salam. 2002. Screening of some brinjal varieties and lines against brinjal shoot and fruit borer, L. orbonalis Guenee. Pak. J. Biol. Sci. 5(10): 1032-1040.

Mahesh, P and U.B. Men. 2007. Seasonal incidence of Leucinodes orbonalis on brinjal. Ann. Plant. Prot. Sci. 15(2): 498-499.

Naik, V., C. Babu, R.P. Arjuna, P.V. Krishnaya and R.V. Sriviivasa. 2008. Seasonal incidence and management of L. orbonalis Guenee on brinjal. Ann. Plant. Prot. Sci. 16(2): 329-332.

Naresh, J.S., V. Malik, J.S. Balam and K.S. Khokar. 1986. A new record of Trathala sp. A larval endoparasite attacking brinjal fruit borer, Leucinodes orbonalis Guen. Bull. Entomol. New Delhi. 27(1): 74.

Patnaik, H.P. 2000. Flower and fruit infestation by brinjal shoot and fruit borer, Leucinodes orbonalis Guenee-damage potential vs. weather. Veg. Sci. 27(1): 82-83.

Rashid, M.A., S.N. Alam, F.M.A. Rouf and N.S. Talekar. 2003. Socio economic parameters of brinjal pest control in Jessore district of Bangladesh. Technical 
Bulletin No. 29. Shanbua, Taiwan. AVRDC-The world vegetable centre. AVRDC publication No. 03-556. 29p.

Regupathy, A., N.J. Armes, G. Asoken, D.R. Jadhav, R.D. Soundarajan and D.A. Russell. 1997. Best method for insecticide resistance management of Helicoverpa armigera. In: International Conference on Integrated Approach to Combating Resistance. A.L. Devonshine (ed.), April 14-16, 1997. IACR, Rothamsted, Harpendle, UK. 116p.

Sharma, A.K. and R.C. Chhibber. 1999. Effect of exposure periods and insecticides on Leucinodes orbonalis in brinjal. Indian J. Entomol. 61(3): 242-251.

Singh, S.V., K.S. Singh and Y.P. Malik. 2000. Seasonal abundance and economic losses of shoot and fruit borer, Leucinodes orbonalis on brinjal. Indian J. Entomol. 62(3): 247-252.

Singh, N.P., N.S.A. Thakur, A.N. Shyclesha and S. Biswas. 2005. Implementation and Promotion of IPM technology for the control of eggplant shoot and fruit borer (Leucinodes orbonalis Guenee) in Meghalaya and Tripura. Publication No.-17. AVRDC, Post Box: 42, Sanghua, Taiwan 741.

Tewari, G. and H.R. Sardana. 1990. An unusual heavy parasitization of brinjal shoot and fruit borer, Leucinodes orbonalis Guenee by a new braconid parasite. Indian J. Entomol. 52(2):338-341. 